\title{
Hospitalidade e a Busca da Comunidade Ideal em Maria da Fé, MG, Brasil
}

\author{
Andréa Márcia Gonçalves Leandro \\ Sênia Regina Bastos ${ }^{\mathrm{b}}$
}

\section{Resumo}

Esse artigo tem por objetivo analisar o encontro dos outsiders, sejam estes migrantes ou turistas, com a comunidade de acolhimento no contexto dos movimentos migratórios. O marco temporal inicial corresponde ao início da crise da batata e a intensificação da chegada de migrantes e turistas. Os primeiros, atraídos pelo barateamento das terras e pela agricultura natural no município de Maria da Fé-MG; os turistas, pelas baixas temperaturas, que deram à cidade o status de destino indutor de turismo localizado na Serra da Mantiqueira. A metodologia escolhida para esse estudo é a história oral, entretanto observação direta e pesquisa bibliográfica complementam o corpus da pesquisa. Ao empreenderem o deslocamento, os outsiders têm em mente a comunidade ideal, onde imaginam que obterão segurança e serão imediatamente acolhidos. No entanto, no momento do encontro com o grupo estabelecido percebem a distância entre a comunidade ideal e a comunidade real. A definição de comunidade como círculo aconchegante revela identidade com as motivações dos movimentos migratórios em Maria da Fé, porque, de certa forma, esse lugar se afigura como um locus ideológico. Muito acima das belezas naturais e das facilidades da vida na cidade pequena está a questão social, o "estar em comunidade" relativo ao processo de integração que faz mitigar o sentimento de acolhimento para alguns.

Palavras-chave: Hospitalidade; Comunidade; Migração; Turismo; Maria da Fé-MG.

\section{Abstract}

\section{Hospitality and the search for the ideal community in Maria da Fé, MG, Brazil}

This article aims to analyze the encounters of outsiders, whether they are migrants or tourists, with the host community in the context of migration movements. The starting point of this research corresponds to the potato crisis in the municipality of Maria da Fé, state of Minas Gerais, Brazil. It caused the intensification of migrants' arrival, attracted by the low price of its lands as well as its natural farming. In addition, the city is also a destination that attracts tourists because of its low temperatures and in location close to the natural beauties of the mountain chain called Serra da Mantiqueira. As for methodology of the study, we chose the oral history method, complemented by observation and bibliographical research. Outsiders, when undertaking their displacement, have in mind the ideal community, imagining they would find safeness and be immediately accepted. However, after meeting local people they realize the distance between the ideal community and the real one. The definition of community as a cozy circle reveals an identification with the motives of the migration movements to Maria da Fé, as this place looks like an ideological locus. However,

a. Mestre em Hospitalidade pela Universidade Anhembi Morumbi, São Paulo, São Paulo, Brasil. E-mail: andreatino@hotmail.com

b. Doutora em História pela Pontifícia Universidade Católica de São Paulo (PUC-SP). Docente do Programa de Pós-Graduação mestrado e doutorado em Hospitalidade pela Universidade Anhembi Morumbi, São Paulo, São Paulo, Brasil. E-mail: bseniab@terra.com.br 
beyond some facilities for making life easy in a small city and the natural beauties there is the social issue of "being in the community" related to the integration process that sets up the feeling of welcome for some people.

Keywords: Hospitality; Community; Migration; Tourism; Maria da Fé-MG.

\section{Resumen}

\section{Hospitalidad y la búsqueda de la comunidad ideal en Maria da Fé, MG, Brasil}

Este artículo tiene el objetivo de identificar y analizar el encuentro de los outsiders, sean migrantes o turistas, con la comunidad de acogida en el contexto de los movimientos migratorios. El marco temporal inicial corresponde al inicio de la crisis de la patata y la intensificación de la llegada de migrantes y turistas. Los primeros, atraídos por el abaratamiento de las tierras y por la agricultura natural en el Município de Maria da Fé-MG; los turistas, por las bajas temperaturas que dieron a la ciudad el estatus de destino inductor de turismo, localizado en la sierra Mantiqueira. La metodología elegida para este estudio es la historia oral, entretanto la observación directa y la investigación bibliográfica complementan el corpus del trabajo. Al emprender el desplazamiento, los outsiders tienen en mente la comunidad ideal, donde imaginan que obtendrán seguridad y serán acogidos inmediatamente. Sin embargo, en el momento del encuentro con el grupo establecido, perciben la distancia entre la comunidad ideal y la real. La definición de comunidad como círculo acogedor revela identidad con las motivaciones de los movimientos migratorios en Maria da Fé, porque, de cierta forma, ese lugar se figura como un locus ideologico. Por encima de las bellezas naturales y de las facilidades de la vida en la ciudad pequeña está la cuestión social, el "estar en comunidad" relativo al proceso de integración que hace mitigar el sentimiento de acogida para algunos.

Palabras clave: Hospitalidad; Comunidad; Migración; Turismo; Maria da Fé-MG.

\section{INTRODUÇÃo}

Tanto a migração quanto o turismo constituem formas de mobilidade, impactam a sociedade de destino e se relacionam entre si por mecanismos econômicos e culturais que influenciam a procura por espaços, demandas e investimentos. Caracterizado como uma forma de migração de duração variável, o turismo gera fluxos de migração de trabalho para fornecer os serviços demandados pelos turistas, além de produzir consumo, estimular o estabelecimento de segunda residência, migração de aposentadoria, migração de estilo de vida e migração sazonal. Esses fluxos se direcionam para lugares dotados de recursos específicos, afetam a oferta de trabalho, instituem inovações e provocam mudanças nas imagens culturais dos lugares (Hall \& Williams, 2002).

Embora tais fatores não possam ser generalizados, as dinâmicas estabelecidas entre os membros de uma comunidade com o outsider, quer esse vise a visitação turística, quer vise se estabelecer permanentemente nessa sociedade, são pautadas pela desconfiança ou até mesmo pela hostilidade. $\mathrm{O}$ acolhimento ao outsider também implica em uma variedade de fenômenos, motiva preocupações relativas ao local do encontro e às responsabilidades do anfitrião, bem como conduz às implicações éticas e políticas de sua admissão. De caráter polissêmico e natureza complexa, a hospitalidade comporta diversidade de aspectos e sentidos. Investigada a partir de diversos campos disciplinares, os estudos abordam a hospitalidade desde a perspectiva do turismo, da migração, até as formas comerciais 
de hospitalidade no setor turístico ou no âmbito dos serviços, bem como aspectos filosóficos e políticos (Molz \& Gibson, 2007).

A busca da comunidade ideal motiva as migrações desde tempos remotos. No encontro com a comunidade de acolhimento, por vezes o migrante descobre que a comunidade sonhada e idealizada pode não estar ao seu alcance. A comunidade idealizada é o mote de alguns deslocamentos de caráter permanente ou temporário para Maria da Fé, cidade pequena do Sul de Minas Gerais, com pouco mais de 16 mil habitantes, num dos pontos mais altos da Serra da Mantiqueira, cuja paisagem, clima de montanha, cultivo da oliva e agricultura natural, têm atraído muitos. Os migrantes buscam ali uma espécie de Shangri-la, uma comunidade ideal para visitar ou viver.

O objetivo geral deste artigo é identificar e analisar como se deu o encontro dos outsiders com a comunidade de acolhimento no contexto dos movimentos migratórios, notadamente no que tange à comunidade realmente existente e aquela idealizada pelo migrante. 0 estudo das relações estabelecidas entre a comunidade e o migrante sob a perspectiva da hospitalidade é relevante na medida em que estabelece parâmetros para a reflexão sobre o que motiva a visitação à uma comunidade, bem como acerca do tipo de acolhimento que a comunidade oferta ao visitante e, possivelmente, ao turista.

Esse trabalho foi realizado tendo-se como metodologia a história oral, por meio da realização de entrevistas com a comunidade e os outsiders, cujos depoimentos foram gravados e tratados. Para Alberti (2013), a história oral é um método de pesquisa e não um fim em si mesmo, trata-se de um meio de conhecimento. Afirma igualmente a autora, que a história oral somente se justifica no contexto de uma investigação científica articulada com um projeto de pesquisa previamente definido. Por isso, antes mesmo de pensar em história oral é necessário haver questões, perguntas que justifiquem uma investigação ${ }^{1}$.

Segundo a autora "entrevistas de história oral pressupõem a relação com o método biográfico: seja concentrando-se sobre um tema, seja debruçando-se sobre a vida do depoente e os cortes temáticos efetuados em sua trajetória ...." (Alberti, 2013, p. 48).

0 artigo encontra-se dividido em sete partes, incluída essa introdução e procedimentos. Depois, apresenta a cidade Maria da Fé. A quarta parte trata a comunidade real, aquela realmente existente, e a imaginária, que se origina do campo do utópico, do desejo e dos anseios que cada migrante traz consigo. Na quinta parte, aborda-se a questão do modus de acolhimento da comunidade aos que desejam ali se fixar. A sexta parte revela como a comunidade de recepção pode manifestar seu poder por meio da hospitalidade, no que se refere à aceitação ou não daqueles que chegam. E por fim, arremata-se com a conclusão.

\section{PROCEDIMENTOS METODOLÓgICOS}

Os dados e informações, que documentam esse estudo, foram coletados por meio de observação direta, pesquisa bibliográfica e documental, e depoimentos, que buscam uma abordagem verídica e objetiva do tema proposto. No que se refere à metodologia da história oral: "As fontes são os entrevistados e as elaborações que fazem de suas

1. A discussão apresentada neste artigo integra a dissertação de mestrado Hospitalidade e movimentos migratórios contemporâneos no município de Maria da Fé-MG (1990-2015), apresentada como requisito para obtenção do título de mestre em Hospitalidade pela Universidade Anhembi Morumbi-SP. 
histórias. Mergulhar nas narrativas, transcrevê-las, ouvi-las e lê-las dezenas de vezes é privilégio do pesquisador que trabalha com história oral" (Rouchou, 2008, p. 29).

Por se tratar de tema contemporâneo, a história oral se afigurou como a melhor escolha, inclusive, porque as narrativas e vivências das pessoas demonstram como se dá o encontro entre os de fora e a comunidade de acolhimento, que é o elemento vivo e pulsante deste trabalho. Embora não fossem as únicas fontes, as narrativas dos entrevistados tiveram papel de destaque em razão de esse fenômeno estar acontecendo nesse momento histórico, nessa comunidade específica.

A seleção dos entrevistados (outsiders e comunidade) foi conduzida pelos objetivos do estudo e pela importância das experiências vividas por eles. No que tange às entrevistas com os 10 migrantes, buscou-se compreender como se desenvolveu o encontro com a comunidade. Esses migrantes vivenciaram fatos que respondem algumas das questões levantadas ${ }^{2}$. Foi ouvida a comunidade anfitriã (seis pessoas) e essa oitiva teve como eixo central fatos presenciados ou conhecidos sobre suas percepções dos movimentos migratórios contemporâneos. Quanto ao tipo de entrevista, foram ao mesmo tempo temáticas e, por vezes, histórias de vida. Segundo Alberti (2013, p. 48), as entrevistas temáticas são aquelas que versam prioritariamente sobre a participação do entrevistado no tema escolhido, enquanto as de história de vida têm como centro de interesse o próprio indivíduo na história.

Para viabilizar o tratamento de dados, as entrevistas foram gravadas e depois transcritas e editadas. Procedeu-se à eliminação de gírias, erros gramaticais e de concordância, bem como vícios de linguagem comuns e coloquialismos. Alguns termos foram mantidos a fim de preservar a leveza e originalidade dos depoimentos $^{3}$. Optou-se por entremear o texto com os depoimentos transcritos em itálico, de acordo com a pertinência temática.

Quadro 1 - Perfil dos entrevistados

\begin{tabular}{|l|l|l|l|l|l|l|l|}
\hline \multicolumn{3}{|c|}{ Migrante } & \multicolumn{4}{c|}{ Comunidade anfitriã } \\
\hline id. & \multicolumn{1}{|c|}{ sexo } & ocupação & origem & id. & sexo & \multicolumn{1}{c|}{ ocupação } & origem \\
\hline E1 & feminino & agricultora & São Paulo & E6 & masculino & comerciante & Maria da Fé \\
\hline E2 & feminino & agricultora* & São Paulo & E7 & feminino & comerciante & Maria da Fé \\
\hline E3 & masculino & professor & Grécia/São Paulo & E8 & masculino & $\begin{array}{l}\text { artista/ } \\
\text { designer }\end{array}$ & Maria da Fé \\
\hline E4 & masculino & agricultor* & São Paulo & & & \\
\hline E5 & feminino & agricultora* & São Paulo & & & \\
\hline & $*$ Ocupação declarada por ocasião da entrevista, todavia, antes de migrar possuía outra \\
\hline
\end{tabular}

2. Após um contato inicial com os entrevistados, obteve-se deles um acordo em participar para a entrevista, mostrando-lhes a importância do seu depoimento para esse estudo, descrevendo os propósitos do trabalho, deixando claro o respeito por ele. Buscou-se a autorização prévia do entrevistado, também, para gravar a entrevista, dotando-lhe de autonomia para exclusão de trechos dos depoimentos, bem como a possibilidade de desligar o aparelho, quando não desejassem o registro de algum trecho de suas falas. Embora os entrevistados tenham sido identificados no documento de autorização de entrevista e divulgação, optou-se por não revelar seus nomes, posto que o alcance de um artigo científico não determina suas fronteiras. A fim de evitar equívocos, as identidades dos entrevistados foram preservadas, por meio do recurso de apresentação como E1, E2 etc.

3. Os entrevistados foram consultados sobre o conteúdo da transcrição e assinaram o termo de consentimento. 
O Quadro 1 sistematiza o perfil dos entrevistados, cujos depoimentos foram incorporados ao artigo, ou seja, não foram inseridos à análise as entrevistas de cinco migrantes e de três membros da comunidade em razão do objetivo delineado para esta abordagem. Do perfil dos entrevistados nota-se a atração motivadora das terras baratas de Maria da Fé, dado que quatro dos cinco selecionados são agricultores, ao passo que dois marienses se dedicam à atividade comercial e outro é designer, artista e o idealizador do projeto Gente de Fibra ${ }^{4}$.

\section{MARIA DA FÉ: UM LUGAR COM NOME DE MULHER}

Maria da Fé ${ }^{5}$ se inscreve nos circuitos turísticos Terras Altas da Mantiqueira, Caminhos do Sul de Minas e até mesmo pelo Circuito das Águas, ${ }^{6}$ aspecto que reforça sua potencialidade econômica, mas que de certa forma indica a dificuldade de definição de uma identidade turística, apesar de seu reconhecimento como destino indutor de turismo (Emmendoerfer, 2014). A localização geográfica de relativa proximidade com as principais capitais do Sudeste, estando a 335 quilômetros do Rio de Janeiro, a 436 de Belo Horizonte e 281 de São Paulo, faz com que a cidade não seja apenas um lugar de produção agrícola, ou que sirva apenas de ponto de apoio à atividade agrícola.

Dotada de menos de 50 mil habitantes (IBGE, 2019), o que a configura como uma cidade pequena, Maria da Fé apresentava um produto interno bruto que superava alguns médios e grandes municípios do estado, em função de ter sido a maior produtora de batata e sementes de batata do país até o início dos anos 1990. No entanto, uma crise no setor exigiu ações alternativas para a recuperação da economia e, com a participação do Serviço de Apoio às Micro e Pequenas Empresas (Sebrae) e da Secretaria de Turismo da cidade, juntamente com a população local, iniciaram-se, dentro do programa de governo do estado, o projeto Minas Recebe, iniciativas de fomento da atividade turística. Nesse contexto, começa a crescer o interesse dos turistas pela cidade, que vinham em busca do clima de montanha (cidade mais fria do Sudeste) e atraídos pela cultura da oliva ou simplesmente para apreciar as obras dos artesãos e designers da cidade.

Pessoas interessadas em adquirir terras, cujos proprietários não tinham mais condições de manter, em função da falência da monocultura, começaram a chegar, e a cidade foi, paulatinamente, mudando seu conteúdo (Santos, 2003) ${ }^{7}$. Considerada uma das sete cidades sagradas do Brasil para os místicos, atualmente é sede de algumas instituições que, de certa forma, influenciam parte dos

4. O projeto Gente de Fibra foi criado para apoiar o projeto turístico. Apesar de não existir mais, manteve a valorização da simplicidade, considerada um dos expoentes da identidade cultural da cidade (E8 - comunidade de acolhimento - entrevista realizada em 27/05/2015).

5. A paróquia remonta a 27 de outubro de 1908, cuja denominação deriva do nome da estação ferroviária, inaugurada no dia 27 de junho de 1891, que homenageou a fazendeira pioneira da região, Dona Maria da Fé. A referida estação acabou por representar a matriz geradora da nova vila, a Vila de Campos de Maria da Fé, elevada à categoria de cidade em 1917.

6. Sua inscrição no Circuito das Águas decorre da proximidade à cidade de São Lourenço, Minas Gerais, Brasil.

7. As cidades mudam de conteúdo a partir de transformações que alteram o que era aparentemente estático. A cidade "dos notáveis" destacava-se pela exacerbada importância dada às suas personalidades marcantes que eram o padre, o tabelião, a professora primária, o juiz, o promotor 
movimentos migratórios e de visitação, são exemplos: a Sociedade Brasileira de Eubiose $^{8}$, a Universidade Holística, e a Associação dos Produtores de Agricultura Natural de Maria da Fé (Apanfé).

\section{COMUNIDADE REAL E IMAGINÁRIA}

Para Bauman (2003, p. 7) as palavras têm significados, porém, algumas delas guardam sensações. Comunidade é uma dessas palavras que sugere uma coisa boa. Para o autor, o que quer que signifique comunidade, é bom tê-la, é bom estar em uma. Para ele, comunidade produz uma sensação boa por causa dos significados que a palavra carrega, todos eles prometendo prazeres e, às vezes, as espécies de prazeres que se gostaria de experimentar, mas que não se alcança mais. Segundo o autor, comunidade é um lugar cálido, confortável e aconchegante. É como um teto sob o qual se pode abrigar da chuva pesada, como uma lareira diante da qual se pode aquecer as mãos num dia gelado.

Na comunidade pode haver discussões, mas estas são amigáveis, pois todos estão tentando tornar o estar juntos ainda melhor e mais agradável. Infere-se, desse pensamento, que o sentimento de solidariedade experimentado na comunidade evoca a sensação de segurança e pertencimento.

0 modus de acolhimento pela comunidade revela o conceito de hospitalidade analisado neste trabalho. A hospitalidade é aqui tratada como o encontro (Godbout, 1997) entre os outsiders e a comunidade (Elias \& Scotson, 2000). Embora aparentemente simplista, esse conceito encerra grande complexidade, uma vez que o encontro entre os dois universos nem sempre se dá de forma pacífica, havendo sempre mutações em ambos os polos. Os depoimentos dos migrantes a seguir, revelam a importância da aceitação e acolhimento no encontro com a comunidade: " $O$ contato com a pessoa que me vendeu a terra me inseriu em alguns meandros da cidade, na comunidade" (E1 - migrante - entrevista realizada em 17/05/2015); "Eu conheço gente que foi embora daqui porque não conseguiu se entrosar, não conseguiu fazer parte da comunidade. Agora quem tem sítio e quer viver mais afastado, esses conseguem ficar" (E2 - migrante - entrevista realizada em a 19/05/2015).

0 encontro entre os dois universos é, normalmente, permeado de conflitos de interesses. 0 estranho, aquele que chega (foris - do reino de Hermes) traz consigo, além de sua bagagem cultural, o desejo de ser assimilado, aceito. A comunidade é o elemento fixo da relação (domnis - do reino de Héstia), é a anfitriã, a herdeira da terra e da cultura local.

A hospitalidade, no que concerne ao encontro, ganha importância capital num contexto de acolhimento. $\mathrm{O}$ encontro com a comunidade e seu modo de receber revela se a comunidade idealizada pelo forasteiro se concretiza ou não.

A comunidade utópica é para o migrante, num primeiro momento, o lugar do "querer bem" e da convivência fraterna que suplanta a mera existência de um agrupamento de pessoas. Observa-se um divisor de águas entre o momento

e o telegrafista. Ela cedeu lugar à cidade econômica, onde são imprescindíveis: o agrônomo (que antes vivia nas capitais), o veterinário, o bancário, o piloto agrícola, o especialista em adubos, o responsável pelos comércios especializados etc. (Santos, 2003, p. 56).

8. A Sociedade Brasileira de Eubiose existe na cidade de Maria da Fé há mais de 25 anos e tem atraído movimentos migratórios para aquela localidade. 
do encontro do forasteiro com a comunidade de recepção e o momento em que o outsider passa a sentir-se aceito, integrado. Percebe-se que os momentos em grupo se tornam mais agradáveis quando se encontra a comunidade imaginada. Embora as diferenças existam, são tratadas de modo cordial, pois há uma preocupação de que o "estar junto" seja cada vez melhor.

Segundo Bauman (2003), na comunidade imaginária, aquela idealizada pelo outsider, pode-se contar com a boa vontade e auxílio dos outros, nesse sentido, o dever individual, pura e simplesmente é ajudar uns aos outros e, assim, ter o direito de esperar obter a ajuda necessitada. 0 autor arremata afirmando que no momento atual e implacável que vivemos, comunidade é um tipo de mundo inacessível. 0 sentimento de comunidade se desvanece à medida em que as cidades crescem e que a velocidade imposta pelo capitalismo dita o ritmo das relações humanas.

Williams (2003, p. 9) define comunidade, hodiernamente, como sendo outro nome dado ao paraíso perdido, um lugar que se encontra no futuro, para onde se deseja ardentemente retornar, que promove a busca contínua dos caminhos que levem até lá. Entre as pessoas que se deslocaram para Maria da Fé, alguns percebem a cidade como essa espécie de paraíso mesmo, e há quem compare a comunidade à terra prometida do Antigo Testamento:

Quando chegamos aqui fomos procurar emprego justo em faculdade. O povo via o curriculum de físico, mestrado na USP, doutor... logo contratava, mas eu travava na hora de falar em público. Então para ficar aqui, eu tive que aprender a falar para sobreviver. E eu vinha num processo de espiritualização, eu sentia minha vida como um novo êxodo, é como se eu estivesse no Egito, num deserto, perdido, como escravo e encontrei minha Canaã, por analogia, aqui é minha terra prometida. Pra mim, tem essa simbologia. O povo aqui tem uma religiosidade muito bonita. Essa comunidade me acolheu. Eu sou grego de sangue, católico ortodoxo. (E3 - migrante - entrevista realizada em 15/11/2015)

Esses pensamentos, de certa forma, sintetizam o elemento psicológico, o desejo que orienta as buscas de alguns dos migrantes contemporâneos que se movem para cidades pequenas ou comunidades rurais, por acreditarem que ali a communitas, enquanto sentimento, permanece viva. Os depoimentos de alguns entrevistados revelam que essa comunidade é para eles uma espécie de "terra prometida", onde reinam a paz, a saúde e a convivência fraterna entre pessoas de diversas procedências e os membros da comunidade de acolhimento.

Infere-se, por meio dos depoimentos, que a comunidade idealizada é o motor de alguns movimentos migratórios em Maria da Fé. 0 ser humano demonstra o desejo de encontrar um lugar mítico, onde seu sonho de paz se realizará, e alguns o realizam. Mas para outros, a comunidade idealizada não se concretiza na e empreendem um movimento de retorno ao mundo real, ou começam a amargar a sensação de expulsão do paraíso, ou não conseguem permanecer, ou se condenam ao degredo, enfim, nasce um sentimento de reserva. No melhor dos mundos, encontram o que foram buscar, mas cientes dos custos dessa conquista.

A definição de comunidade como círculo aconchegante em Bauman (2003), revela certa identidade com as motivações dos fluxos migratórios contemporâneos em Maria da Fé, porque, de certa forma, esse lugar se afigura como um locus ideológico para alguns migrantes que ali foram viver. 
Lócus ideológico é o oposto do que Bauman (2003, p. 17) chama de comunidade real, trata-se de um lugar imaginado, criado artificialmente. A comunidade real é aquela que, ao contrário, leva à compreensão de que lógica e sonhos humanos dificilmente andam juntos.

Ideológico ou não, o conceito de comunidade aqui referido, movimenta as buscas daqueles que um dia deixaram a cidade grande à procura desse lugar ideal. Observa-se que a comunidade de Maria da Fé reúne algumas características que a aproximam daquela buscada pelos forasteiros, mas, de modo algum, pode-se dizer que a convivência e a integração deles, nesse espaço, se dão de forma pacífica e imediata. Não basta o clima, o relevo, as possibilidades de vida ao ar livre. Muito acima das belezas naturais e das facilidades de vida numa cidade pequena está a questão social, o "estar em comunidade". É o processo de integração que faz mitigar o sentimento de comunidade para alguns, uma vez que esse revela a comunidade real: "A gente se sente muito bem aqui, em termos de saúde, de tranquilidade, essa região aqui é muito especial." (E4 - migrante - entrevista realizada em 28/05/2015); "Aqui é meio que um paraisinho assim. E também a questão de ser uma das cidades sagradas para a Eubiose" (E5 - migrante - entrevista realizada em 28/05/2015).

Gostei da região achei bonito. Conheci várias cidades e podia ser qualquer uma delas, mas aqui era um lugar bonito tinha água em relativa abundância. E eu acabei optando por aqui, apesar da distância de São Paulo. Não escolhi Maria da Fé de antemão. $O$ grupo [Apanfé] ${ }^{9}$ me acolheu e isso foi bom, facilitou minha estada. Na minha escolha ter conhecido o grupo, não foi fundamental, mas ajudou. (E1 - migrante - entrevista realizada em 17/05/2015)

Bauman (2003) fala da comunidade imaginária, atraente, que reproduz a ideia de aconchego, que fatalmente leva o estudioso da hospitalidade a associá-la ao conceito de acolhimento.

A comunidade imaginada é o reino das diferenças. Diferenças entre quem chega e os estabelecidos, entre a cultura estabelecida e a cultura trazida, diferenças entre o ritmo de vida, que os migrantes mesmos definem como "infernal" do grande centro e a vida tranquila na comunidade imaginária. E isso determinará o grau de adaptabilidade e aceitação, fato que pode gerar conflitos de ordens diversas, fazendo com que alguns vejam frustrados seus ideais de communitas. Dos depoimentos de alguns forasteiros é possível abstrair a ideia de que Maria da Fé, no momento da escolha, dessa espécie de paraíso particular, reuniu as características da comunidade ideal que traziam em mente quando deram início a sua busca, mas notadamente, $o$ acolhimento do grupo foi importante para sua permanência. Há diferenças marcantes que distinguem a comunidade dos sonhos e a comunidade realmente existente. Na visão de Bauman (2003, p. 9), uma coletividade que pretende ser a comunidade encarnada, o sonho realizado, e, em nome do todo,

9. A Associação dos Produtores de Agricultura Natural de Maria da Fé (Apanfé) existe há mais de 20 anos e foi criada por agricultores locais que após a crise da batata na cidade, nos anos 1990, decidiram substituir as práticas nocivas ao meio ambiente, da agricultura convencional, pela produção orgânica. Alguns migrantes têm ido viver na cidade, porque para estes, na comunidade ideal, pode-se produzir alimentos saudáveis e viver integrado ao meio ambiente. A associação tem sido, ao longo desses anos, uma porta de entrada na comunidade para aqueles que desejam uma vida saudável e pautada pela produção agrícola sustentável. 
o bem que supõe que essa comunidade oferece, exige lealdade incondicional e trata tudo o que ficar aquém de tal lealdade como um ato de imperdoável traição.

\title{
COMUNIDADE E ACOLHIMENTO
}

Ao sentir-se aceito na comunidade, o forasteiro começa a perceber o preço de sua escolha e, por conseguinte, que o seu acolhimento exige lealdade irrestrita à comunidade a um preço, que normalmente é a perda da liberdade ou de uma parcela desta. Para Bauman (2003, p. 10), há um preço a pagar pelo privilégio de "viver em comunidade" - e ele é pequeno e até invisível só enquanto a comunidade for um sonho. 0 preço é pago em forma de restrição à liberdade, também chamada "autonomia", "direito à autoafirmação" e "à identidade".

Qualquer que seja a escolha, ganha-se alguma coisa e perde-se outra. Não ter comunidade significa não ter proteção; alcançar a comunidade, se isto ocorrer, poderá em breve significar perder a liberdade. A segurança e a liberdade são dois valores igualmente preciosos e desejados que podem ser bem ou mal equilibrados, mas nunca inteiramente ajustados e sem atrito.

Nesse contexto, perder a liberdade significa ceder uma parcela de sua individualidade cultural, moral, para ser coletivo. "Os de fora" entendem esse movimento de várias maneiras: "As pessoas conhecem a gente mais do que a gente imagina. É uma linguagem muda. A ação é uma coisa muito forte no ser humano. Essa persistência, essa coerência." (E4 - migrante - entrevista realizada em 28/05/2015).

\begin{abstract}
A gente era observado sem saber... Atéo que a gente consome... Uma vez veio uma pessoa perguntar se eu tinha uns potinhos de um produto que eu consumia em quantidade. Fiquei impressionada. Como a pessoa podia saber o que eu comia na minha casa? Outra coisa, é que às vezes não estávamos em casa e chegava alguém nos procurando. Algum vizinho dizia que se não estivéssemos em casa, provavelmente estaríamos na Eubiose. Como pode isso?! Quandoé a gente quem chega numa cidade é muita gente para conhecer, mas quando você é a novidade, um corpo estranho, todo mundo quer saber quem é. Assustava-nos o quanto éramos observados. (E5 - migrante - entrevista realizada em 28/05/2015)
\end{abstract}

Quando trata da urbe ideal, Léonard-Roques (2011) afirma que esta pode se apresentar como um refúgio para o imaginário frente às insatisfações do presente. A urbe utópica é paradoxalmente um lugar pouco hospitaleiro, que limita os espaços de liberdade (Léonard-Roques, 2011, p. 502). 0 lugar que consagra o desejo de evasão e o triunfo da fantasia pode estabelecer limites estritos que se afiguram como o reverso da hospitalidade, ou seja, ter em mente apenas o desejo de perfeição do encontro com a comunidade ideal pode gerar a ilusão de que o acolhimento e a hospitalidade são uma consequência natural do encontro, no entanto, pode-se afigurar como uma experiência de exclusão e/ou hostilidade.

A comunidade como imersão ingênua da união humana é, cada vez mais, possível apenas em sonhos, o que torna ainda mais instigante o estudo sobre os deslocamentos humanos motivados pela busca de uma comunidade ideal, quer migratórios, quer turísticos.

Do ponto de vista fático, o que ocorre é que ao transpor a soleira de uma comunidade receptora, o forasteiro nem sempre encontrará esse círculo aconchegante, 
uma vez que os próprios códigos locais (normas de convivência) o manterão à distância até que seja aceito. E esse, talvez, seja o momento de contato com a comunidade real, diverso da comunidade imaginada (Rosemberg, 2000, p. 16).

Riedfield (apud Bauman, 2003, p. 17) define a comunidade pequena como o "arranjo do berço ao túmulo", o que permite a inferência de que em Maria da Fé, bem como em uma outra comunidade menor, o chamado círculo aconchegante só estará inteiramente disponível aos filhos biológicos daquela terra, ou seja, aos que ali nasceram e ali pretendem morrer (os herdeiros da cultura). Percebe-se que o círculo existe, mas que não basta estar ali para receber suas benesses. Isso se afigura como prova de que a lógica e sonhos humanos não andam juntos:

No início eu fiquei no sítio, depois eu fui para associação [Apanfé]. A maioria dos produtores da associação era da cidade. A associação já tem uns 15 anos. Eu demonstrei interesse em me associar, mas as coisas demoram, parece que te cozinham um tempo. Não sei se é pra conhecer, para saber quem é a pessoa. As pessoas ficam receosas (a desconfiança do mineiro). Com a comunidade de Maria da Fé eu não tenho muito contato, conheço a cidade através da associação. (E1 - migrante - entrevista realizada em 17/05/2015)

O mineiro é desconfiado, mas com o forasteiro isso é mais forte. Porque quando a gente chega, a primeira pergunta é "você é filho de quem"? E eu sou só filho da minha mãe e ninguém conhece minha mãe. (E4 - migrante - entrevista realizada em 28/05/2015)

A sobrevivência da comunidade ideal num mundo globalizado revela que não houve queda das fronteiras, mas que, no entanto, elas se erguem para proteger os indivíduos que ali se encontram das incertezas individualmente enfrentadas (Bauman, 2003, p. 21).

Note-se que nos depoimentos acima, aqueles que desejavam sentir-se protegidos pelas fronteiras da comunidade, fazerem parte dela, encontraram toda sorte de barreiras. A começar pelo não pertencimento biológico à terra. Desperta atenção o fato de que a primeira pergunta feita pelos locais é: "você é filho de quem?", porque há a necessidade velada de ser filho da terra. Na mente do migrante, a comunidade imaginada, o círculo aconchegante não quer saber de quem se é filho, suas origens; não há necessidade desse credenciamento. Fato que, de certa forma, aumenta o impacto da chegada, pois se trata do confronto com a realidade.

Outra questão rapidamente percebida pelos de fora é a perda da liberdade em contrapartida ao sentimento de pertencimento e aceitação. Tudo isso coaduna na sensação de ter as portas fechadas em Shangri-la.

Entendem Elias e Scotson (2000, p. 25) que no grupo dos antigos residentes, famílias cujos membros se conhecem há mais de uma geração, estabelecem entre si um estilo de vida comum e um conjunto de normas que por si só representam uma fronteira. Eles observam certos padrões e se orgulham disso. Por conseguinte, o afluxo de recém-chegados é sentido como uma ameaça ao estilo de vida estabelecido. Eles são desconhecidos, não apenas dos antigos residentes, mas entre eles mesmos (os recém-chegados) e isso não lhes dá coesão.

Com o passar do tempo, as famílias tradicionais que frequentavam o clube, eram diferentes. Mesmo os que chegavam de fora, nas férias, era mais gostoso. Com a questão 
da batata, alguns foram enriquecendo e isso foi mudando a cidade. Ninguém fica rico da noite para o dia. Eles se viram com muito dinheiro. E vieram os novos ricos, que se fechavam. E não frequentavam os clubes, não tinham convívio social. Sempre iam para fora, iam para Itajubá, Ubatuba, tinham casas de praia em Ubatuba. E foi desintegrando. (E6 - comunidade de acolhimento - entrevista realizada em 27/06/2015)

Hospitalidade e comunidade são temas com estreita ligação, pois o sentimento de pertencimento é resultado do acolhimento. Sendo a hospitalidade o dom do espaço (Godbout, 1997); espaço a habitar, a atravessar ou contemplar, Gotman (1997) revela a capacidade imanente do espaço de produzir hospitalidade e acolhimento, sublimando a importância de ser admitido no interior, ou seja, transpor a soleira, o direito de estar dentro.

A necessidade de estar dentro da comunidade, de entrosamento (acolhimento/pertencimento), demanda um tempo necessário a esta, para que se identifique se o indivíduo que pleiteia sua entrada revela algum tipo de empatia com o grupo estabelecido. $\mathrm{Ou}$, como na hospitalidade antiga, é necessário que um membro da comunidade apadrinhe a estada do forasteiro nos limites desta, até que o mesmo receba o visto, a aceitação tácita de permanência (Grassi, 2004, p. 53).

Os três relatos que se seguem revelam esse viés: E2 quando aponta que o homem que lhe vendeu a terra a introduziu nos meandros da comunidade; E4 e E5 , ao afirmarem que o banco onde trabalhavam fez a ponte entre eles e a comunidade; e E6 ao falar do amigo, artista local, que lhe abriu algumas portas, e do casal da loja de material de construção. Mesmo se sentindo admitidos no círculo aconchegante, relembram sua condição eterna de forasteiros.

Eu tive uma pessoa que me ajudou muito no começo. Ele me ajudou a fazer contatos. Hoje eu tenho uma relação muito boa com proprietários de comércio, o casal da loja de material de construção foi um bom apoio também no início. Eu tenho crédito na cidade. (E2 - migrante - entrevista realizada em 19/05/2015)

No banco, quando nós chegamos, recebemos um acolhimento fantástico, o gerente também e os colegas. Esse acolhimento também nos ajudou. $O$ banco foi o padrinho, aquele que facilita, abre portas. (E5 - migrante - entrevista realizada em 28/05/2015)

E como a gente era do banco, tem um emprego, as pessoas não nos veem assim tão soltos.... (E4 - migrante - entrevista realizada em 28/05/2015)

Ser admitido... ser aceito... não foi de cara, levou uns anos para as pessoas aceitarem a gente. Eu me sinto integrada, acolhida, mas sei que não sou daqui. (E5 - migrante entrevista realizada em 28/05/2015)

Note-se que o primeiro contato "dos de fora" com a comunidade de Maria da Fé acontece, normalmente, tendo como pano de fundo as relações comerciais. 0 casal da loja de material de construção foi mencionado em quase todas as entrevistas, não apenas como comerciantes, mas de forma afetuosa pelos outsiders, como se, da relação comercial houvesse nascido uma relação de amizade, que de certa forma, abre portas, oferece crédito e apoio; faz com que o extraneo, já não se sinta tão solto e desterritorializado. 
A pessoa procura a gente, porque somos honestos. Quem chega, seja buscando o calor humano ou um tijolo, a gente precisa estar aberto a oferecer. Nós viemos no mundo para servir. Tem que ser puro de coração. A pessoa quando é acolhida, ela sente estímulo para ficar. Nós não distinguimos ninguém, todos são importantes da mesma maneira. (E7 - comunidade de acolhimento - entrevista realizada em 27/06/2015)

Esses supostos "padrinhos" dos forasteiros na cidade são, de certa forma, o elo perdido entre a hospitalidade arcaica e a contemporânea. 0 acolhimento sem reservas é algo inimaginável contemporaneamente, uma vez que a sociedade se consolida na exclusão. Para Grassi (2004, p. 53), a complexidade das leis escritas, ou não, que regem a chegada "dos de fora" e sua instalação no mundo antigo e no mundo contemporâneo demonstra que a hospitalidade é complexa, difícil, às vezes impossível, que o incondicional se choca incessantemente com o condicional.

A conquista de espaço e confiança da comunidade pode levar muito tempo. Trata-se de um processo permeado de reveses que fazem o migrante se sentir totalmente integrado num dia e no outro desejar estar em outro lugar, principalmente em Minas Gerais, onde reina a fama de desconfiado do povo mineiro.

Na mitologia, as figuras de Sísifo e Tântalo são condenadas por rebeldia e desobediência aos deuses e são obrigados a tarefas repetitivas. Sísifo foi condenado a, por toda a eternidade, rolar uma grande pedra com suas mãos até o cume de uma montanha, sendo que toda vez que ele estava quase alcançando o topo, a pedra rolava novamente montanha abaixo até o ponto de partida, por meio de uma força irresistível, invalidando completamente o duro esforço despendido.

Tântalo, por enganar os deuses num banquete a eles oferecido, foi sentenciado a não poder saciar sua fome e sede, visto que, ao se aproximar da água, esta escoava e ao erguer-se para colher os frutos das árvores, os ramos moviam-se para longe de seu alcance sob a força do vento. A expressão "suplício de Tântalo" demonstra o sofrimento daquele que deseja algo aparentemente próximo, porém inalcançável.

Assim, há uma analogia entre as figuras mitológicas mencionadas e os migrantes que são obrigados a retomar sua tarefa de se integrar continuamente, sempre que estão muito próximos de alcançar seus objetivos. Os migrantes contemporâneos em busca da comunidade ideal são obrigados ao exercício diário de se fazerem integrar, ainda que não tomados pelo sentimento de pertencimento à communitas, muitas vezes, sentem-se obrigados a refazer esse movimento eternamente ou serem condenados ao isolamento.

Fazendo analogia com a figura mitológica de Tântalo, Bauman (2003) declara que a esperança de alívio e tranquilidade que torna a comunidade com que sonham tão atraente, será impulsionada cada vez que acreditam, ou lhes é dito, que o lar comum que procuram foi encontrado. Às agonias de Tântalo se juntam - tornando-as ainda mais sofridas - as de Sísifo. A comunidade "realmente" existente será diferente daquela dos sonhos, mais semelhante a seu contrário, ou seja, aumentará seus temores e insegurança em vez de diluí-los ou deixá-los de lado (Bauman, 2003, p. 22).

\section{O PODER DA COMUNIDADE}

Há uma máxima no direito romano que diz: ubi pedis, ibi pátria, ou seja, onde estão seus pés aí está a sua pátria. No entanto, para sentir que a comunidade ideal é sua nova pátria, o migrante precisa sentir-se assimilado. 
0 processo de assimilação é tortuoso e pode redundar em sentimento de expulsão, quando os valores trazidos entram em choque com os valores estabelecidos e os códigos locais. 0 migrante, por vezes, terá a sensação de estar adstrito ao poder da comunidade e, que sua vinculação a esta depende, não apenas de sua vontade de pertencer, mas principalmente de sua capacidade de abdicar de parcelas de sua individualidade, deixando de lado o sentimento de ser uno para sentir-se pluribus.

A identidade coletiva da comunidade é um fator de resistência e poder, afigurando-se esta, outrossim, como um microcosmo de estrutura moral e social rígidas, onde quem não se integra, amarga o isolamento social que faz com que o migrante se sinta um apátrida na terra onde resolveu se instalar, o sentimento de reserva.

Silva e Sant'Anna (2014) descrevem o confronto entre o turismo e identidades culturais, analisando os impactos psicossociais nessa relação. Ponto de contato com este trabalho, uma vez que este analisa o encontro entre as realidades móveis (deslocamentos e deslocados) e a cultura estabelecida (identidade coletiva).

Numa perspectiva conceitual os autores definem identidade cultural como um conjunto de características próprias e exclusivas de uma pessoa que lhe trará um sentimento de pertença, de inclusão e de fixação em relação a um determinado grupo. É a identidade cultural que faz com que o indivíduo perceba seu papel na sociedade e seja parte do grupo que com ele compartilha das mesmas referências (Silva \& Sant'Anna, 2014, p. 6).

Segundo Weeks (1993, p. 208-209) o mais forte sentido da comunidade costuma vir dos grupos que percebem as premissas de sua existência coletiva ameaçada e por isso constroem uma comunidade de identidade que lhes dá uma sensação de resistência e poder. Incapazes de controlar as relações sociais em que se acham envolvidas, as pessoas escolhem o mundo para adaptá-lo ao tamanho de suas comunidades e agem politicamente a partir dessa base. 0 resultado é com frequência um particularismo obsessivo como modo de enfrentar e/ou lidar com a contingência.

Recriar fragilidades e debilidades individuais muito reais na forma da potência (imaginária) da comunidade resulta em ideologia conservadora, pragmática e exclusivista. 0 conservadorismo (voltar às raízes) e o exclusivismo ("eles" são, coletivamente, uma ameaça para "nós", coletivamente) são indispensáveis para que a comunidade imaginária gere as redes de dependências que a tornarão real. "Se as pessoas definem uma situação como real, ela tende a se tornar real para que suas consequências possam operar".

0 "comunitarismo" ocorre mais naturalmente às pessoas que tiveram negado o direito à assimilação. Tiveram negada a escolha - procurar abrigo na suposta "fraternidade" do grupo nativo é sua única opção. Voluntarismo, liberdade individual, autoafirmação são sinônimos de emancipação em relação aos laços comunitários, da capacidade de desconsiderar a atribuição herdada - e foi isso que lhes foi negado quando não receberam o convite para a assimilação, ou este lhes foi retirado. (Thomas apud Bauman, 2003, p. 92)

0 migrante que não se submete ao poder do microcosmo (comunidade) tem duas opções: declina de sua individualidade e se submete à ideologia conservadora exclusivista e pragmática, tornando real a comunidade imaginada ou resiste a tudo isso, se permitindo ser uno, renunciando a comunidade imaginada e aceitando a reserva. 
Eu não estou fechada à comunidade. Os muros são uma proteção energética, não são sinônimo de isolamento. $O$ medo é uma barreira natural que elas mesmas colocam. Eu mantenho isso para nos proteger. Eu não faço parte de grupos da cidade, eu não tenho amigos chegados que me visitem em minha casa. Eu vivo aqui no meu isolamento, tenho funcionários que moram aqui na região, mas a minha ligação com a cidade é comercial, para suprir minhas necessidades. (E2 - migrante - entrevista realizada em 19/05/2015)

As declarações da migrante entrevistada refazem os passos daqueles que se recusam a abrir mão de parte de sua individualidade cultural para receber a acolhida da comunidade imaginada. Percebe-se que os que resistem ao poder do chamado da comunidade, na verdade, não abrem mão do seu "eu" e tampouco das memórias trazidas consigo de outros lugares. Santos (2003, p. 330) é enfático a esse respeito quando afirma que o homem de fora é portador de uma memória, espécie de consciência congelada provinda com ele de outro lugar:

O lugar novo o obriga a um novo aprendizado e uma nova formulação... quanto mais instável e surpreendedor for o espaço, tanto mais surpreendido será o indivíduo, e tanto mais eficaz será a operação de descoberta... A noção de espaço desconhecido perde a conotação negativa e ganha um acento positivo, que vem do seu papel na produção da nova história.

Contra os dissidentes ou contra os que resistem à cultura estabelecida em nome da preservação de sua individualidade cultural, a comunidade impõe de forma silenciosa, por um juízo de exceção, a pena de degredo. Note-se que "cultura" vira sinônimo de fortaleza sitiada, e numa fortaleza sitiada os habitantes têm que manifestar diariamente sua lealdade inquebrantável e abster-se de quaisquer relações cordiais com estranhos (Bauman, 2003, p. 127).

É contraditório sonhar uma comunidade ideal no mundo dos indivíduos e das individualidades, num mundo onde a própria busca interior, por um lugar ideal, também é um sonho individual. Maria da Fé, enquanto comunidade, e seus filhos biológicos ou adotados, passam ao largo dessa discussão amplamente filosófica. Mas muitos pensadores debruçaram-se sobre o tema. Em Léonard-Roques (2011, p. 504) verifica-se que a comunidade modelo, "carregada de esperanças está no fundamento do gênero utópico que se desenvolve na esteira da Utopia (1516) de Thomas More. Ela é a fuga para fora da realidade... o universo descrito é imaginário: utopia é a ilha de lugar nenhum".

Os estabelecidos (coesos enquanto comunidade) criaram para si um estilo de vida que obviamente poderá gerar estranhamento àqueles que chegam. São perceptíveis alguns padrões de comportamento, ditados pelo poder da comunitas, como a desconfiança, o silêncio em determinadas situações e o tempo de fazer cada coisa em momento próprio.

A comunidade num primeiro momento recebe com reservas. Dizem alguns que em razão da legendária desconfiança do mineiro ${ }^{10}$. Por isso, o migrante é observado. Não há sentimento de desprezo ou ódio contra os forasteiros, ao contrário, há um

10. Em alguns relatos, os migrantes afirmaram que o mineiro é desconfiado, "come quieto", mas não constitui objetivo dessa pesquisa a discussão sobre mineiridade. No entanto, a suposta desconfiança foi tratada sobre vários vieses, dentre eles, como sinal de respeito a "quem vem lá" como traço da topofilia e mesmo como uma característica do povo que vive cercado por montanhas. 
desejo geral que este permaneça ali e ajude no desenvolvimento do município, mas fica claro que este passa por um período de observação velada.

Se a pessoa chega e ninguém acolhe, ela vai embora. Esses que estão chegando são desbravadores como aqueles que vieram antigamente. Os novos migrantes estão trazendo novas condições. Por exemplo, teve um casal que veio pra cá, a mulher dava aulas de pintura, balé e esses também que vem abrindo a cabeça das pessoas com relação ao perigo dos agrotóxicos, trazendo a agricultura orgânica. (E7 - comunidade de acolhimento - entrevista realizada em 27/06/2015)

A chegada dos "de fora" está sendo muito bom para Maria da Fé... Para ser aceito aqui, a pessoa precisa ter uma conduta... A aceitação depende mais de quem chega do que do mariense. (E6 - comunidade de acolhimento - entrevista realizada em 27/06/2015)

Há apenas um tempo de observação. Afirmado pelos forasteiros e pelos estabelecidos que faz parte do comportamento taciturno de quem vive em meio às montanhas. Em uníssono, ouve-se que para o outsider, que chega de coração e mente aberta, haverá sempre um lugar no colo maternal de Dona Maria da Fé (a comunidade):

Quem chega aqui normalmente, não precisa da aceitação e da compreensão da cidade, eles chegam com seus projetos e seguem. As pessoas são preconceituosas; ainda existe preconceito velado, mas o mariense vai te receber muito bem, e a pessoa vai romper essa fronteira. (E8 - comunidade de acolhimento - entrevista realizada em 27/05/2015)

Esse negócio de, "pode entrar que a casa é sua" do mineiro tem vários estágios. Tem uma fase de contato meio superficial, de "oi"! super gentil, mas só depois que ele [o mineiro] confia em você, ele escancara. Mas no início é meio aparente, eles ficam te observando... "O mineiro diz que para se considerar amigo, precisa comer um saco de sal junto". (E5 - migrante - entrevista realizada em 28/05/2015)

A comunidade percebe a importância dos de fora, não só para a circulação cultural, bem como para a movimentação da economia, que nunca mais foi a mesma depois da crise da batata nos anos 1990. Infere-se do exposto que para a comunidade de recepção, quem ditará o tom do diálogo com a comunidade é o próprio deslocado:

Nossa atitude de respeito nos permitiu ser respeitados também. Nós temos muitos amigos que entraram com tudo. Chegaram na padaria reclamando que está demorando, que o troco está errado, tem fila... essas pessoas não ficam. Alguma coisa aborta. Essas pessoas são abortadas daqui. (E5 - migrante - entrevista realizada em 28/05/2015)

Para ser aceito aqui a pessoa precisa ter uma conduta ... 99\% das pessoas que vem pra cá são pessoas boas. Esse um por cento que não é aceito, é porque ele quer se impor. Então a própria pessoa se rejeita. Quem chega aqui querendo mudar tudo, não será aceito. Tem que respeitar os princípios da cidade. (E7 comunidade de acolhimento - entrevista realizada em 27/06/2015)

Se o de fora respeita a cultura, os códigos locais e está disposto a ceder uma parcela de sua individualidade cultural, pode entrar que a casa é sua! No entanto, 
se o tom é áspero e o desejo do forasteiro é o de impor sua cultura, seu ritmo de vida da metrópole, então que construa muros bem altos.

\section{CONCLUSÃO}

Conclui-se que existe um sentimento latente de comunidade em Maria da Fé, como elemento interno e psicológico, um verdadeiro círculo aconchegante, nas palavras de Bauman (2003).

Alguns forasteiros vieram para a cidade motivados pela ideia da comunidade imaginária e ao se depararem com a realidade, alguns a leram como fechada e reacionária, outros, como muito observadora e reservada, mas os marienses se dizem muito hospitaleiros com todos que chegam, desde que estes não imponham sua cultura, cheguem de coração aberto e estejam dispostos a contribuir.

0 confronto com a realidade faz com que o forasteiro descubra que Maria da Fé, como toda comunidade ideal, é o reino das diferenças e que, para ser acolhido e sentir-se pertencente, deve ceder parcela de sua liberdade e de sua identidade cultural. 0 comunitarismo, às vezes, o faz sentir-se vigiado e invadido.

0 "não ser filho da terra" é uma barreira, vê-se que a primeira pergunta que o forasteiro ouve normalmente é: "você é filho de quem?" E uma vez não sendo filho de ninguém dali, ele precisará de um padrinho. Constata-se com esse fato que a comunidade guarda resquícios da hospitalidade antiga, pois ainda há quem receba sem reservas, e para permanecer ali é preciso que alguém de dentro (padrinho) respalde a estada do estranho.

Infere-se que a identidade coletiva da cidade é um fator de resistência, pois aqueles que não se adaptam aos códigos locais são condenados ao isolamento e em última instância terminam por deixar a comunidade. Observa-se que a comunidade de Maria da Fé não se fecha a quem chega, ao contrário, a maioria entende como benéfica a chegada dos de fora. Compreendem a importância econômica da atividade turística e procuram a ela se adaptar.

Nesse sentido, a noção de comunidade atua como um diferencial da cidade, pondera-se, todavia, a importância de estudos que forneçam parâmetros para potencializar esse aspecto e a hospitalidade sem, no entanto, afetar a relação e o acolhimento que se estabelece entre a comunidade e o turista. Salienta-se ainda como pauta de investigações futuras, o papel da visitação turística na decisão de fixação permanente em Maria da Fé.

\section{REFERÊNCIAS}

Alberti, V. (2013). Manual de história oral. Rio de Janeiro, RJ: FGV Editora.

Bauman, Z. (2003). Comunidade: a busca por segurança no mundo atual. Rio de Janeiro, RJ: Jorge Zahar.

Elias, N. \& Scotson, J. L. (2000). Os estabelecidos e os outsiders: sociologia das relações de poder a partir de uma pequena comunidade. Rio de Janeiro, RJ: Jorge Zahar.

Emmendoerfer, M. L. (2014). Análise do desenvolvimento turístico e da denominação designada pelo governo para qualificar as cidades como destinos indutores de turismo em Minas Gerais, Brasil. RT\&D, 21/22, 139-151. 
Godbout, J. T. (1997). Recevoir, c'est donner. Communications, 65, 35-48. Recuperado de http://bit.ly/2waC1oo

Gotman, A. (1997). La question de l'hospitalité aujourd'hui. Communications, (65), 5-19. Recuperado de https://bit.ly/2DV20Ve

Grassi, M. C. (2004). Transpor a soleira. In Montandon, A. O livro da hospitalidade: acolhida do estrangeiro na história e nas culturas (pp. 45-53). São Paulo, SP: Senac.

Hall, C. M., \& Williams, A. M. (2002). Tourism and migration: new relationships between production and consumption. Berlim: Springer Science/Business Media.

Instituto Brasileiro de Geografia e Estatística (IBGE). (2019, maio 10). Maria da Fé. Recuperado de http://bit.ly/2JSBKyr

Léonard-Roques, V. (2011). Cidade-refúgio: a urbe ideal. In Montandon, Alain. O livro da hospitalidade: acolhida do estrangeiro na história e nas culturas (pp. 501-508). São Paulo, SP: Senac.

Molz, J. G., \& Gibson, S. (2007). Introduction: mobilizing and mooring hospitality. In Mobilizing hospitality: the ethics of social relations in a mobile world (pp. 1-26). Farnham: Ashgate.

Rosemberg, G. (2000). Cultural diversity and political priority, France. La Nouvelle lettre Internationale.

Rouchou, J. (2008). Noites de verão com cheiro de jasmin. Rio de Janeiro, RJ: FGV Editora. Santos, M. (2003). A natureza do espaço. São Paulo, SP: Hucitec.

Silva, D. R., \& Sant'Anna, P. A. (2014). Turismo e confronto com a identidade cultural: impactos psicossociais da atividade turística em Diamantina-MG. Revista Turismo em Análise, 25(3), 649-676.

Weeks, J. (1993). Rediscovering values. In Squires, J. (Org.). Principled positions. Londres: Lawrence and Wishart.

Recebido em: 08/11/2016

Aprovado em: 19/05/2018

\section{CONTRIBUIÇÕES}

Andréa Márcia Gonçalves Leandro: Definição do problema de pesquisa e objetivos, desenvolvimento da proposição teórica, realização da revisão bibliográfica e fundamentação teórica, escolha dos procedimentos metodológicos, revisão crítica do manuscrito, redação do manuscrito, e adequação do manuscrito às normas da RTA.

Sênia Regina Bastos: Definição do problema de pesquisa e objetivos, desenvolvimento da proposição teórica, escolha dos procedimentos metodológicos, e revisão crítica do manuscrito. 